\title{
Evolution of Precision Agriculture Computing towards Sustainable Oil Palm Industry
}

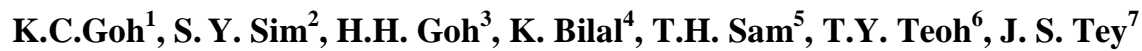 \\ ${ }_{1,4,5,6,7}$ Department of Construction Management, Faculty of Technology Management and Business, \\ Universiti Tun Hussein Onn Malaysia, 86400 Parit Raja, Batu Pahat, Johor, Malaysia \\ ${ }^{2}$ Department of Electrical Engineering Technology, Faculty of Engineering Technology, \\ Universiti Tun Hussein Onn Malaysia, 86400 Parit Raja, Batu Pahat, Johor, Malaysia \\ ${ }^{3}$ Department of Electrical Engineering, Faculty of Electrical and Electronic Engineering, \\ Universiti Tun Hussein Onn Malaysia, 86400 Parit Raja, Batu Pahat, Johor, Malaysia
}

\begin{tabular}{l}
\hline \hline Article Info \\
\hline Article history: \\
Received Feb 1, 2018 \\
Revised Apr 12, 2018 \\
Accepted Apr 20, 2018 \\
\hline
\end{tabular}

\section{Keywords:}

Precision technology

Oil palm

System development life cycle

sustainability

\begin{abstract}
Precision technology elements have not been implemented yet into the sustainable oil palm industry because the knowledge and technology gap. To resolve the gaps, promote sustainability and integrate the technologies, Oil Palm Management System (OPAMS) was introduced. The precision technologies in OPAMS comprises of Geographical Information System (GIS), Global Positioning System (GPS), remote sensing and yield monitoring. A phase by phase System Development Life Cycle (SDLC) methodology was used to generate the said system with feedbacks from oil palm planters as the inputs for OPAMS's key features. OPAMS ultimately aims to increase the awareness of the industry on the benefits of utilizing technology to improve plantation performances, increase business and environmental sustainability.
\end{abstract}

Copyright (C) 2018 Institute of Advanced Engineering and Science. All rights reserved.

\section{Corresponding Author:}

K.C.Goh,

Department of Construction Management, Faculty of Technology Management and Business,

Universiti Tun Hussein Onn Malaysia,

86400 Parit Raja, Batu Pahat, Johor, Malaysia.

Email: kaichen@uthm.edu.my

\section{INTRODUCTION}

Current studies stated that the world needs to provide more food in the coming four decades as compared to eight thousand years ago. This put the global society in a worrisome position. Throughout the years, crop yields reduced due to climate change, scarcer water supply and extending land degradation. To date, public concern on sustainability of oil palm industry is still an issue, as the usage of pesticide is unavoidable. Oil palm is the one of the most important economic source of Malaysia. Malaysia is the second largest producer and the largest exporter of crude palm oil. The total coverage area of plantation for palm oil grew from 3.38 million hectares in 2000 to 4.85 million hectares in 2010, which constitute about increase of $43.49 \%$ of area use. Malaysia's oil palm industry was the first to apply the environmental quality control for sustainability continuity, and the imposed regulation is the Environmental Quality (Prescribed Premises) (Crude Palm Oil) Regulations, 1977 which promulgated under the Environmental Quality Act.

Indonesia and Malaysia constitutes about 85\% of the world's palm oil, and Malaysia is the second largest palm oil producer in the industry. Generally palm oil industry production and manufacturing caused lots of environmental damages such as air pollution, water pollution which leads to threatening of human health, also causes some serious land issues like soil erosion, and sometimes even contributes to the socialeconomic issue at rural area development due to the existence of foreign labors [1]. 
The industry is still continuously face new challenges of different nature and dimensions in terms of regulatory requirements, trade obligations, technological advancement and new industrial and consumer demands [2]. Malaysia palm oil industry demonstrated a good sustainable practice of Integrated Pest Management (IPM) system and zero burning technique. However according to the industry players, the IPM system was unable to control output amount for pesticide or herbicide usage and have wastage issue as well. As such, a means of better sustainable ways is needed to overcome this issue. A preliminary study was carried out in the year 2014 in regards to the manipulation of technologies for the sustainable development of oil palm industry. The aforesaid case study highlighted two important issues: the monopolization of aerial technology in Malaysia and the high adoption cost, whereby these two issues become challenges for most of the plantation small and medium holders from engaging this effective fertilizer application. In this case, the aerial application technology utilizes key concepts such as VRT and GPS. To resolve such issue, a system of Oil Palm Management System (OPAMS) were introduced in this study

Where the ideas of such integration is adopted from other precision technology application in agriculture industry such as grape vine virticulture [3]. There are many other sustainable agriculture terms comprises of technology advancement elements in it, such as "holistic management", Site-Specific Management, rice integrated crop management, and precision agriculture. All the terms have one goal, to achieve sustainability throughout the process of crops production. The precision agriculture cycle consists of many stages which includes soil mapping, crop condition mapping, soil condition mapping, yield mapping, data analysis, and treatment map modelling, and applied GPS on agriculture automobiles such as tractors [4]. Meanwhile millions of people rely on palm oil to feed their families and support their livelihoods. Demand for edible oil will continue to grow as the world population approaches 9 billion by 2050 [5].

Precision farming has been suggested as a means of strategic management for agricultural crops on a smaller scale than total farm area, based on the use of information technology and agronomic know-how [6]. In management, one of the most important is to manage the information system as well. In the precision agriculture, the most important information system is the GIS and the yield mapping information, which the parameters and the data decide most of the changes in its production through management of chemical fertilizers and herbicide as compared to other technologies or information system within the precision agriculture. Robot simulations were used too for the activities in precision agriculture [7].

The advancement of technologies has since changed the precision agriculture industry. However past researches and studies did not fully focus or address for the application of all precision agriculture elements in the oil palm growing industry. The Malaysia oil palm industry lacks of precision agriculture technology research and development in a whole. The precision technology of OPAMS model revolves on the idea as shown in the Figure 1.

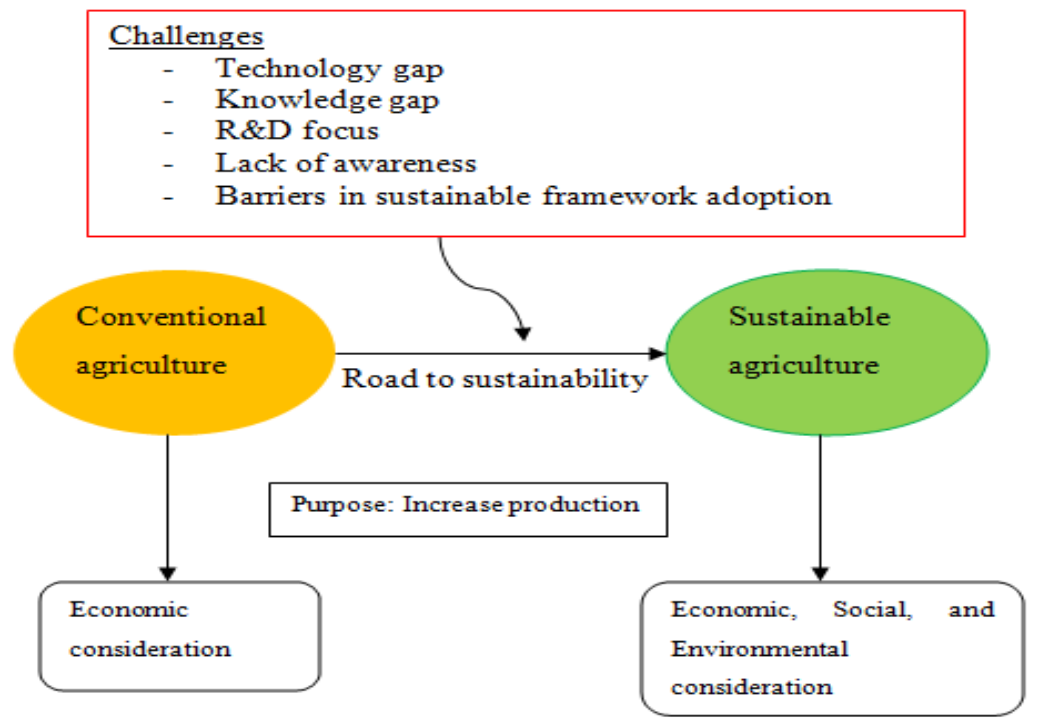

Figure 1. Roadmap the sustainable agriculture 


\section{PRECISION AGRICULTURE TECHNOLOGIES}

The technologies in precision farming are made up of Global Positioning System (GPS), yield monitoring and mapping, grid soil sampling and variable-rate fertilizer (VRT) application, remote sensing, crop scouting, and information management [8-10] Research on biomass model for palm oil shows the current remote sensing technology used in the mapping is through satellite application. Technology gap for the studies in applying UAV to VRT in precision farming are found as well [11]. If is found that most of the research and current technology applied in precision agriculture concerns for the use of remote sensing with the application automobiles and satellite to get image for the data analysis such as NDVI, soil mapping and yield monitoring.

There are several types of PA software. The common software are used to generate maps (e.g. yield, soil); software to filtering collected data; software to generate variable rate applications maps (e.g. for fertilizer, lime, chemicals); software to overlay different maps; and software to provide advanced geostatistical features.

In sustainable agriculture, there are many available and applied tools such as the GPS (Global Positioning System), VRT (Variable Rate Technology), Sensors, Monitors, mapping softwares, there are researches of conducting the data collection for NDVI but just focus on the data analysis. Most of the researches' NDVI data didn't focus on the comparison of technology used for NDVI data collection, such as the UAV, tractor, or satellite. Furthermore, the current remote sensing application focus on the utilization of satellite rather than the aerial ones [12]

The most common indicators used in the precision agriculture are thermal readings and NDVI. The GIS software provides the functions and tools needed to store, analyze, and display geographic information. The GIS is helpful in determining the plants' condition, the soil condition, formulates the Generating High Resolution DSM for high accuracy of crop analysis.

In recent years, many researchers have applied wireless sensor networks in agriculture [13].

These systems are useful particularly in applying pesticides, lime, and fertilizers and in tracking wide planters/drills or large grain-harvesting platforms. GPS navigation tools can replace foam for sprayers and planter/drill-disk markers for making parallel swaths across a field. Navigation systems help operators reduce skips and overlaps, especially when using methods that rely on visual estimation of swath distance and/or counting rows. This technology reduces the chance of misapplication of agrochemicals and has the potential to safeguard water quality. Also, GPS navigation can be used to keep implements in the same traffic pattern year-to-year (controlled traffic), thus minimizing adverse effects of implement traffic [14].

\subsection{Remote Sensing in Agriculture}

Remote sensing is an all-encompassing term for a range of technologies which allow indirect measurement of something, often from afar. Examples include satellite or airborne imagery, or electromagnetic (EM38) soil survey. Remotely sensed data, obtained either by aircraft or satellite contains useful data regarding the information on soil condition, plant growth, weed infestation etc. This type of information is cost effective and can be very useful for site-specific crop management programs [15]. Aerial Photography [1] method has shown more promising result than satellite imagery method due to some benefits like operation below cloud, proper or intentional revisit time, higher spatial resolution etc [16].

UAV have great potential for rangeland management and several advantages over satellites and where piloted aircraft can be deployed quickly and repeatedly, its vehicle cost is less costly and safer than piloted aircraft, flexible in terms of flying height and timing of missions and able to obtain imagery at subdecimeter resolution [17]. UAV thus plays an important role in the future development of the precision agriculture technology for its benefit to overcome the inadequate frequency of satellite surveys or disturbing cloud cover conditions from satellite imagery [18]. Agriculture plays a dominant role in economies of both developed and undeveloped countries. Satellite and airborne images are used as mapping tools to classify crops, examine their health and viability, and monitor farming practices. Agricultural applications of remote sensing include crop type classification, crop condition assessment, crop yield estimation, mapping of soil characteristics, soil management practices and compliance monitoring [19].

Good management provides sound recommendations and reliable management decisions of the oil palm trees. One of the techniques is the application of remote sensing which is used as a tool to determine decisions about the oil palm plantations. NDVI is often used worldwide to monitor drought and predict agricultural production. NDVI allows the interpreters to interpret that the covered vegetation is healthy and can help us to predict that it is productive palm. It is important to know the NDVI of the oil palm stand to enable the plantation manager to gauge the level of effectiveness in the management of the palms. It is recommended to allow the NDVI analysis on wider age stand intervals [20]. 


\subsection{Yield Monitoring}

Numerous approaches exist for estimating crop yields with remote sensing. As the term mentioned, the yield monitoring is the process of calculate and record crop yield or grain yield data using devices for the plantation. There are many examples of effective use of spatial data in crop research and in answering specific farm management questions, but no one has been able to link spatial data and overall farm profitability. Kent Olson, University of Minnesota, was unable to find a statistical relationship between yield monitor use and farm profits in data from farm business associations in his state [21].

Overall, there is clear evidence that crop yield estimation is possible with remote sensing, with good accuracies in some cases [18]. One of the example of the analysis of data from the captured image and information in the remote sensing is leaf and soil analysis by using High resolution SPOTTM and IKONOSTM satellite. From this, it can be clearly seen that the application of GIS, GPS and remote sensing to the yield monitoring.

\subsection{Variable Rate Technologies (VRT)}

The VRT apply remote sensing, GIS and GPS technologies together. According to [11], there VRT systems that were identified are such as biomass imagery by Silverfox, One Rinex system mounted on a tractor and connected to a yield monitor, and LiDRA.

With VRT applicators can apply seeds, fertilizer, and pesticides to suit different sections of a field depending on soil conditions, nutrient needs, and the severity of pest problems, thereby economizing on inputs without sacrificing yield. VRTs are seeders, sprayers, and other fertilizer and pesticide application equipment that can be continually adjusted during field operations to optimize the application of inputs depending on field conditions [22].

\section{ELEMENTS OF PRECISION TECHNOLOGIES}

In short, the remote sensing tools combined with the GPS system to forms the geo-referencing for the crops of GIS. All the 3 technologies were used for the application of VRT and yield monitoring. The yield monitoring is also known as yield mapping, and it was used as a data to be inputted into the VRT system as well. To summarize it, the relationships of the 5 technologies for the precision agriculture are illustrated in Figure 2.

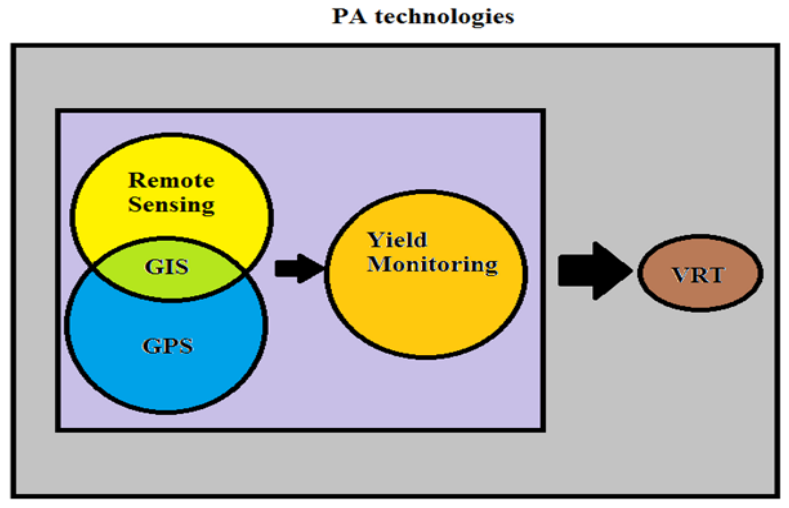

Figure 2. Relationship of Precision Agriculture Technologies

\section{MATERIAL AND METHODS}

The research was carried out using System Development Life Cycle (SLDC) model. SDLC is a structure followed by a development team within the softwareorganization. Variety of SDLC models are used widely for developing a software system such as waterfall model, iterative model, v-shaped model, spiral model etc. The overall purpose of having a SDLC model is to produce a high quality system which would meet the users' expectation and demand. Choice of employing any sort of SDLC model is fully independent. Generally there are a few system development phase: Understanding the problem, deciding an action plan, coding for the planned solution, testing the actual program, deployment and maintenance of the product [23], presented a simple diagram which shows the SDLC model phases in general in Figure 3. 


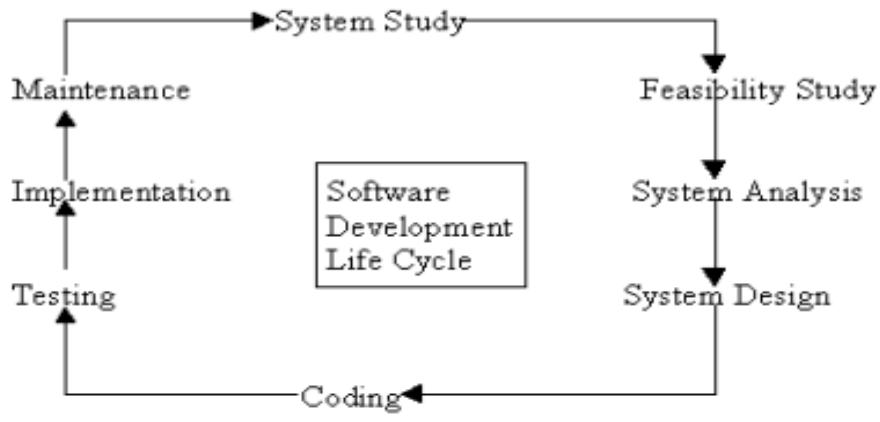

Figure 3. SDLC model phases (source from: [23])

Although the choice of SDLC models are highly defined by the developer itself, however the advantages and disadvantages of the existing SDLC model can be identified so to ensure the compatibility of the model versus the problem statement. Research by [24] shows several comparison of advantages and disadvantages of the SDLC model, at the same time indicated that iterative model is suitable for continuous software development, where the development is divided into smaller parts in development process [25, 26, 27]. The SDLC model helps to identifies the criteria of OPAMS from the respondents' feedback and thus forms the key criteria for the system, displayed on the OPAMS user interface.

\section{RESULTS AND DISCUSSION}

OPAMS aims at two things, which is integrating the existing precision technologies and enhance the sustainability management model for the oil palm plantation. It determines five major elements which contribute towards the most of the operational process as shown in Figure 4.

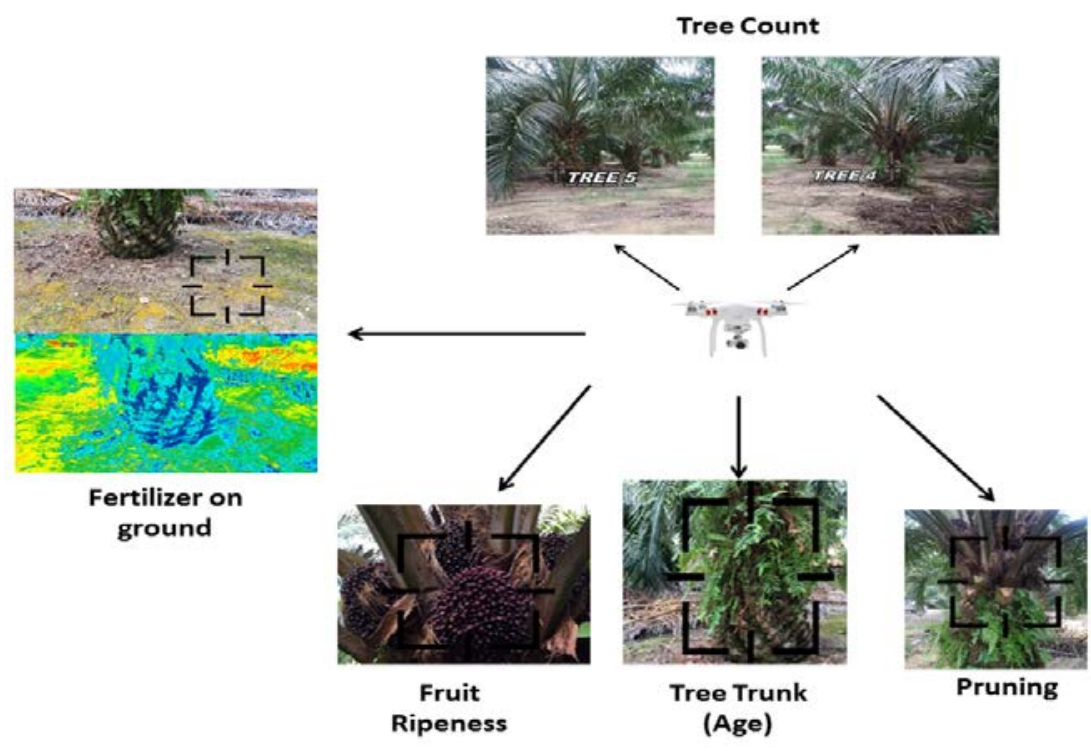

Figure 4. Usefulness and application of OPAMS

From the elements, report of the health condition for each individual palm oil were created and registered into the system from a case study near Sungai Ayer Hitam to test out the OPAMS system. In this testing phase, major functions such as tree counting, tree trunk inspection, fertilizer application inspection, fruits inspection etc. are tested on the software reliability that whether it is functioned properly or not. The result were shown as the Figure 5 and Figure 6. 


\begin{tabular}{|c|c|c|c|c|c|c|c|c|}
\hline \multirow{3}{*}{$\begin{array}{l}\text { Project Cover } \\
\text { Tree Count } \\
\end{array}$} & \multicolumn{8}{|c|}{ Oil Palm - Health \& Maintenance System Report } \\
\hline & \multirow{2}{*}{ No } & \multirow{2}{*}{ Tree 1D } & \multirow{2}{*}{$\begin{array}{l}\text { Frond Pruning } \\
\text { (No. of Fronds) }\end{array}$} & \multirow{2}{*}{$\begin{array}{l}\text { Ripeness } \\
\text { (\%) }\end{array}$} & \multirow{2}{*}{\begin{tabular}{|c|} 
Fertilizer Application \\
$(\%)$
\end{tabular}} & \multicolumn{3}{|c|}{ Tree Trunk Inspection } \\
\hline & & & & & & Age (Month) & Diameter (mm) & Height (mm) \\
\hline & Tree 1 & DT2017987AC & 0 & 20 & 50 & 36 & 90 & 210 \\
\hline \multirow[t]{2}{*}{ Frond Pruning } & Tree 2 & DT2017974AC & 5 & 70 & 80 & 46 & 100 & 250 \\
\hline & Tree 3 & DT2017625AC & 4 & 60 & 40 & 45 & 95 & 220 \\
\hline \multirow{3}{*}{ Fresh Fruit Bunch } & Tree 4 & DT2017655AC & 0 & 10 & 30 & 30 & 115 & 190 \\
\hline & Tree 5 & DT2017644AC & 6 & so & 0 & 37 & 98 & 260 \\
\hline & Tree 6 & DT2017233AC & 5 & 30 & 60 & 48 & 100 & 270 \\
\hline \multirow[t]{2}{*}{ Fertilizer } & Tree 7 & DT2017123AC & 0 & 20 & 70 & 38 & 120 & 230 \\
\hline & Tree 8 & DT2017238AC & 8 & 0 & 30 & 49 & 85 & 240 \\
\hline \multirow{2}{*}{ Tree Trunk } & Tree 9 & DT2017255AC & 10 & 70 & 90 & 33 & 90 & 180 \\
\hline & Tree 10 & OT2017255AC & 3 & 0 & 30 & 38 & 95 & 190 \\
\hline \multirow{3}{*}{ Report } & Tree 11 & DT2017018AC & 11 & so & 90 & 40 & 100 & 150 \\
\hline & Tree 12 & DT2017275AC & 7 & 0 & 20 & 36 & 80 & 180 \\
\hline & Tree 13 & DT2017645AC & 8 & 0 & 30 & 36 & 85 & 250 \\
\hline natex & Tree 14 & DT2017564AC & 5 & 0 & 0 & 32 & 90 & 180 \\
\hline
\end{tabular}

Figure 5. OPAMS reporting user interface (report)

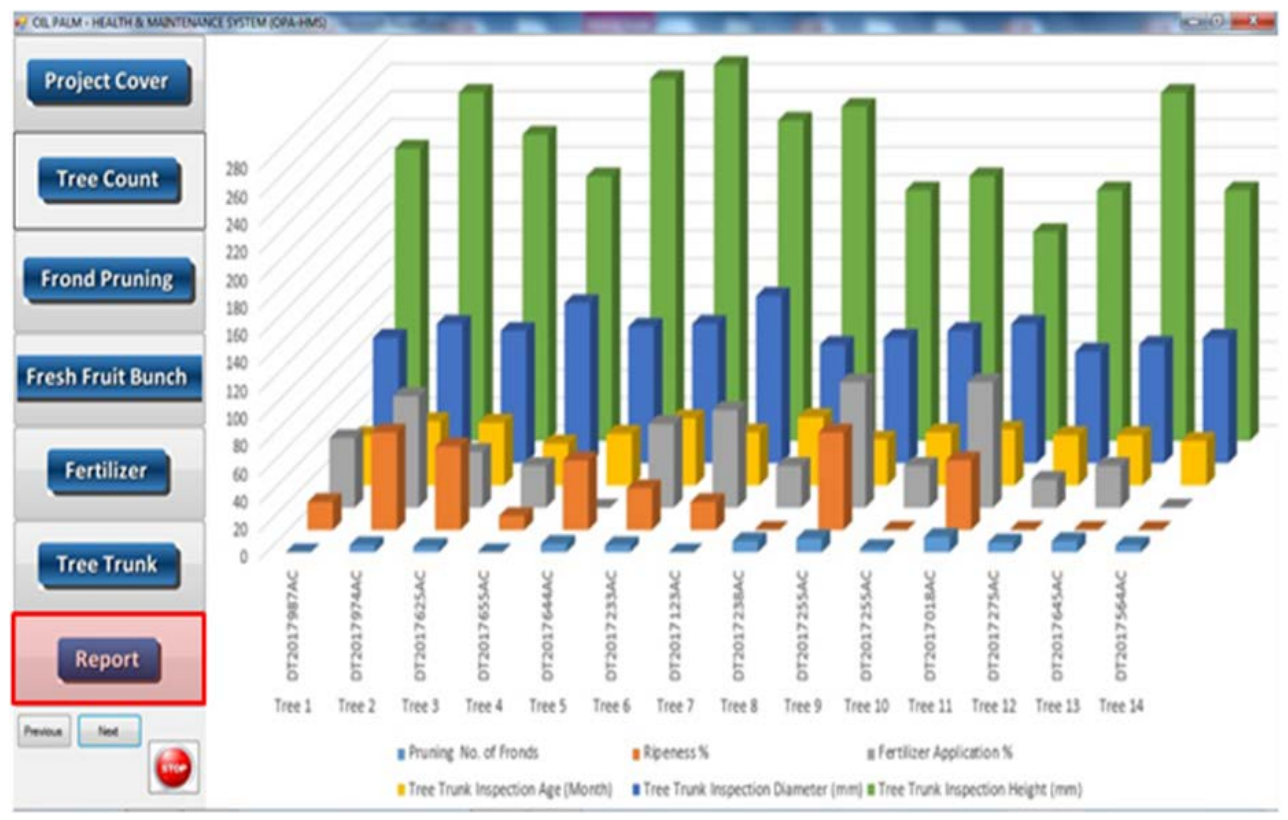

Figure 6. OPAHMS reporting user interface (graph)

To further understand how the system works, it constitute of generally 3 steps for the users to follow to gain the data as shown in the Figure 5 and 6:

1. Drone take off - Camera was installed and the embedded system was connected to the laptop via Bluetooth. Information captured from the camera will be sent to the laptop via Bluetooth.

2. Capture Information - Information are captured for tree count inspection, Tree trunk inspection, fertilizer inspection, fruit ripeness inspection, pruning inspection.

3. Wireless information transferred to OPAMS and analysis of data were shown in the User-Interface (UI)

Precise data can affect the output of the agriculture yield. This means by the data gained from the precision agriculture application can affects the agricultural yield. Precision agriculture scope may be included from genetic control up until the growing of the crops. 


\section{CONCLUSION}

This paper serves to develop a sustainable precision farming system for the palm oil industry by identify the knowledge and technology gap of the application of precision technologies in Malaysia's palm oil industry at the same time. Concurrently, by identifying the current lacking in the industry will be able to serve as a good database for the research to model a better system to improve the industry's sustainable practice. The principle of the system captures visual inspection using remote drones and analysing various elements for the oil palm grower to make cost-related decisions, such as input of labour for pruning and fertilizer amount. OPAMS is the new utilization of the said precision technology elements.

\section{ACKNOWLEDGEMENT}

The authors express gratefully acknowledgment to the industry stakeholders for their valuable contributions towards the success of this research. This research is fully funded by Universiti Tun Hussein Onn Malaysia (UTHM) under Vot: U913, Tier 1 Grant Scheme and Vot: U887, Tier 1 Grant Scheme.

\section{REFERENCES}

[1] Awang ABDN, Kanjappan R, Chin M, Schoneveld G, Potter L and Andriani R. "The local impacts of oil palm expansion in Malaysia; An assessment based on a case study in Sabah State," Center for International Forestry Research (CIFOR) working paper, vol. 78, pp. 1-17, 2011.

[2] Sheil D, Casson A, Meijaard E, Van NM., Gaskell J, Sunderland GJ. et al., "The impacts and opportunities of oil palm in Southeast Asia. Africa," 2009.

[3] Tisseyre B. and Taylor J. "An overview of methodologies and technologies for implementing precision agriculture in viticulture," XII Congresso Brasileiro de Viticultura E Enologia, pp. 45-54, 2006.

[4] Comparetti A. "Precision Agriculture : Past , Present and Future, (SEPTEMBER 2011)." 2015.

[5] Cargill. Cargill Policy on Sustainable Palm Oil. Cargill, Incorporated [Online]. Available: https://www.cargill.com/wcm/groups/public/@ccom/documents/document/palm_oil_policy_statement.pdf

[6] Santos AO, Valeriano MDM., Gonzalez JV. and Carlos A. "Opportunities and limitations for the application of simulation and modeling as a support for precision farming," vol. 011, pp. 1509-1517, 2001.

[7] Emmi L, Paredes Madrid L, Ribeiro APG., and Gonzalez de Santos P. "Fleets of robots for precision agriculture: a simulation environment.," Industrial Robot: An International Journal, vol. 40, pp. 41-58, 2013.

[8] Aubert BA., Schroeder A., and Grimaudo J. "IT as enabler of sustainable farming: An empirical analysis of farmers' adoption decision of precision agriculture technology. "Decision Support Systems, vol. 54, 2012.

[9] Strickland RM, Ess DR., and Parsons SD. "Precision farming and precision pest management: the power of new crop production technologies.," vol. 4, pp. 165-174, 2006.

[10] Swinton S, and Lowenberg DJ. "Global adoption of precision agriculture technologies: Who, when and why? ," Third European Conference on Precision Agriculture, pp. 557-562, 2001.

[11] Robertson M. "The economic benefits of precision agriculture : case studies from Australian grain farms," 2007.

[12] Bello OM. and Aina YA. "Satellite Remote Sensing as a Tool in Disaster Management and Sustainable Development: Towards a Synergistic Approach," Procedia - Social and Behavioral Sciences, vol. 120, pp. 365-373, 2014.

[13] Li S, Peng S, Chen W, and Lu X. "INCOME: Practical land monitoring in precision agriculture with sensor networks," Computer Communications, vol. 36, pp. 459-467, 2013.

[14] Grisso RB and Mark GAG. "Precision Farming Tools: GPS Navigation," Virginia Cooperative Extension Precision Farming Series. , 2009.

[15] Plant RE. "Site specific management: the application of information technology to crop production.," Comput. Electron. Agric, vol. 30, pp. 9-29, 2001.

[16] Mondal P, Basu M, and Bhadoria,PBS. "Critical Review of Precision Agriculture Technologies and Its Scope of Adoption in India," American Journal of Experimental Agriculture, vol. 1, pp. 49-68, 2011.

[17] Rango A, Laliberte A, Herrick JE, Winters C, Havstad K, Steele C, et al., "Unmanned aerial vehicle-based remote sensing for rangeland assessment, monitoring, and management," Journal of Applied Remote Sensing, vol. 30, 2009.

[18] Primicerio J, Di Gennaro SF, Fiorillo E, Genesio L, Lugato EA., Matese, et al. "A flexible unmanned aerial vehicle for precision agriculture," Precision Agriculture, vol. 13, pp. 517-523, 2012.

[19] Levin N. Fundamentals of remote sensing [Online]. Available: http://linkinghub.elsevier.com/retrieve/pii/0301420776900659

[20] Rashid A. and Shariff M. "NDVI OF OIL PALM TREES BY LANDSAT-5 Imagery," presented at the The 33rd Conference on Remote Sensing Pattaya, Thailand, 2012.

[21] Olson KD. and PE., "An economic assessment of the whole-farm impact of precision agriculture," in American Agricultural Economics Association Annual Meeting, ed, 2013, p. 12.

[22] Schimmelpfennig D and Ebel R. On the doorstep of the information age : recent adoption of precision agriculture [Online]. Available: http://search.ebscohost.com/login.aspx?direct=true\&db=agr\&AN=CAT31089147\&site=ehostlive\&scope $=$ cite 
[23] Mishra A and Dubey D. "A comparative study of different software development life cycle models in different scenarios," International Journal, vol. 1, pp. 64-69, 2013.

[24] Rastogi V. "Software Development Life Cycle Models-Comparison, Consequences," International Journal of Computer Science and Information Security, vol. 6, pp. 168-172, 2015.

[25] Goh, H. H., yi Sim, S., Diblawe, D. K., Ali, M. M., Ling, C. W., Chua, Q. S., \& Goh, K. C. Energy Power Plant in Electric Power Distribution Systems Equipping With Distance Protection. Indonesian Journal of Electrical Engineering and Computer Science, 8(1), 192-198. 2017.

[26] Goh, H. H.,yi Sim, S., Mohamed, O. A., Mohamed, A. F., Ling, C. W., Chua, Q. S., \& Goh, K. C.. Assessment of Power System Risk in Cyber-Attacks in View of the Role Protection Systems. Indonesian Journal of Electrical Engineering and Computer Science, 8(1), 184-191. 2017.

[27] Goh, H. H., yi Sim, S., Mohamed, M. A. H., Rahman, A. K. A., Ling, C. W., Chua, Q. S., \& Goh, K. C. Fault Location Techniques in Electrical Power System-A Review. Indonesian Journal of Electrical Engineering and Computer Science, 8(1), 206-212. 2017. 